\title{
The Future of Irrigated Agriculture between Opportunities and Threats
}

\author{
Daniele De Wrachien ${ }^{1 *}$ and Marco Medici ${ }^{2}$ \\ ${ }^{1}$ Department of Agricultural and Environmental Sciences, University of Milan, Milan, Italy \\ ${ }^{2}$ Department of Agricultural and Food Sciences, Alma Mater Studiorum - University of Bologna, Italy
}

\section{The Role Played by Irrigated Agriculture}

Irrigated agriculture is expected to continue to play a major role in achieving sustainability in the food and agriculture sector, through improvements towards food security and quality of life, while conserving the environment.

Especially during the second half of the last century investments in water for agriculture have made a relevant contribution towards sustainability by promoting decent livelihoods, increasing food security and reducing poverty. From 1940 s food production started to outpace population growth, with an average annual crop production growth of $2.0-2.1 \%$ over the period 1969-1999 [1]. Higher yields have been partially achieved due to the expansion of irrigated areas and improvements in water management on irrigated lands [2].

Over the same period irrigation development has increased food stability, lowered food prices, created employment opportunities and increased rural income, with a multiplier effect estimated as between 2.5 and $4[3,4]$. The prevailing point of view is that the impacts of irrigation have been much more significant than simply agricultural development, embracing relevant rural developments, transforming road systems, education, health, and the entire way of life in rural areas [5].

Today, irrigated agriculture has to cope with a number of threats and challenges such as water scarcity, mitigation of negative environmental impacts associated to conventional agriculture, with the opposition of climate change effects.

Any increment of agricultural yields will necessarily rely largely on sitespecific approaches characterized by not only a more accurate estimation of crop water requirements, but also on improvements in operation and management of irrigation and fertirrigation practices.

\section{Problems and Threats}

Global land and water resources are considered to be sufficient to produce food over the next 50 years on the condition that water for agriculture is better manage [5]. But which factors will reshape the future of irrigation and drainage systems?

Today a number of countries are economically constrained and in the condition of not continuing financing irrigation and agricultural research. The decline of public expenditure may bring unpleasant consequences

*Address for Correspondence: Daniele De Wrachien, Professor, Department of Agricultural and Environmental Sciences, University of Milan, Milan, Italy, Tel: +3902503134; E-mail: daniele.dewrachien@unimi.it

Copyright: (C) 2020 De Wrachien D, et al. This is an open-access article distributed under the terms of the Creative Commons Attribution License, which permits unrestricted use, distribution, and reproduction in any medium, provided the original author and source are credited. such as economic stagnation, increases in world food prices and further degradation of the agricultural resource base [5].

A second point relates to production trends. According to future projections in developing countries the share of irrigation to total agriculture production is expected to relevantly increase as global population shift from staple crops to higher value food produce [6]. This trend is associated with investments in food supply chain reliability and precision water application, as already demonstrated in China [7].

In addition, by 2050 approximately two-thirds of the world's people will live in cities [8]. The increasing urbanization will in turn increase water demand, stressing competition between urban and agricultural sectors, and changes the production structure of agriculture.

Thereby, technological improvements capable of increasing the productive capacity of agriculture need to be encouraged at both institutional and private level. The present irrigation infrastructure is deteriorating or aged and need to be preserved and modernized. Water applied has to be maximized, limiting losses and re-using low-quality water effluents: investments are required to improve the existing infrastructure. To balance future water demand shifted by urbanization processes, compensating investment in new supplies and increased water productivity will be required. Also, additional investments in water treatment and conveyance will be necessary in order to reuse urban and industrial wastewater in agriculture [5].

How irrigation and drainage systems will have to adapt to climate changes are issues that institution are compelled to cope with. Climate change represents somehow additional uncertainty towards the scope for increasing water productivity and may additionally hamper the availability of water resources as one of the main concerns regards increased rainfall variability. Reductions in rainfall at tropical latitudes have been already observed [9], while irrigation water withdrawals are currently stressing many of the world's major river basins [10].

Other possible impacts of climate variability include changes in temperature, sea level rise, floods and coastal erosion [11].

\section{Possible Responses}

The aforementioned contingencies may affect planning principles and design criteria which will have to be systematically reviewed, with increased flexibility in planning and design processes in order to incorporate uncertain responses to the various possible climate impacts. Short-term strategies need to be implemented to face long-term uncertainties. Effective programs would have to be implemented within the following contexts:

- Increased stakeholder participation, including governments, professional and research institutions and non-governmental organizations to action programs at international (river basin), national, and regional level.

- Raising expenditure on irrigation and agricultural research, avoiding 
stagnation and increases in food prices and containing degradation of the agricultural resource base.

- Adoption of a comprehensive integrated approach for environmental management of water and land, improving water control capability in terms of quantity and quality.

- Enhanced water supply predictability and increase transparency and accountability to the final user, with water pricing based on measured deliveries.

\section{References}

1. Bruinsma Jelle "World agriculture : Towards 2015/2030 : An FAO Perspective." Earthscan (2003).

2. Charlotte de Fraiture, David Molden and Dennis Wichelns. "Investing in water for food, ecosystems, and livelihoods: An overview of the comprehensive assessment of water management in agriculture." Agric Water Manag 4 (2010): 495-501.

3. Madhusudan Bhattarae, Randolph Barker and A Narayanarnoorthy. "Who benefits from irrigation development in India? Implication of irrigation multipliers for irrigation financing." Irrig Drain 56 (2007): 207-225.
4. Michael Liptona, Julie Litchfieldb and Jean-Marc Faurèsc. "The effects of irrigation on poverty: A framework for analysis." Water Policy 5 (2003): 413-427.

5. Molden David. "Water for food water for life: A Comprehensive assessment of water management in agriculture." Taylor and Francis Group, London, (2007).

6. Thomson KJ. "World agriculture: towards 2015/2030: an FAO perspective." Land Use Policy. 20 (2003): 375.

7. Shibao Lu , Xiao Bai, Wei Li and Ning Wang. "Impacts of climate change on water resources and grain production." Technol Forecast Soc Change 143 (2019):76-84

8. "World Urbanization Prospects: The 2018 Revision." United Nations Department of Economic and Social Affairs, UN iLibrary, (2019).

9. Xuebin Zhang, Francis W Zwiers, Gabriele C Hegerl, F Hugo Lambert, Nathan $P$ Gillett, et al. "Detection of human influence on twentieth-century precipitation trends." Nature 448 (2007): 461-465.

10. Francois Molle. "River Basin Management and Development." International Encyclopedia of Geography: People, the Earth, Environment and Technology. (2017).

11. Daniele De Wrachien. "Impacts of Global Warming on Irrigation and Drainage Development: Climate Change Scenarios and a Strategic Action Program." Int J Environ Sci 6 (2020): 27-33. 